DOI: $10.4274 /$ tpa.46.23

\title{
Çocuk kliniği ergen hemşireliği uygulamaları
}

\section{Adolescent nursing applications in the pediatrics clinic}

\author{
Mahi Bülgün \\ istanbul Üniversitesi Cerrahpaşa Tıp Fakültesi Hastanesi, Çocuk Sağlığı ve Hastalıkları Anabilim Dalı, i̇stanbul, Türkiye
}

\section{Özet}

Ergenler, ergenlik çağının herhangi bir döneminde bir ya da birden çok hastalıkla karşılaşabilirler. Ergenler bazen pnömoni, menenjit gibi akut hastalıkların tedavisi, bazen de diabet, kanser, kronik böbrek yetmezliği, gibi kronik hastalıklarla ilgili ortaya çıkan bazı sorunların çözülmesi için hastaneye yatıılarak tedavi edilirler. Bu makalede hastanede yatarak tedavi gören ergenlere, çocuk kliniği eğitim hemşiresi tarafından danışmanlık ve genel sağlık eğitimi verilmesiyle ilgili hemşirelik yaklaşımı ele alınmıştır. (Türk Ped Arş 2011; 46 Özel Sayı: 12-4)

Anahtar sözcükler: Ergen, danışmanlık, genel sağlık eğitimi, eğitim hemşiresi

\section{Summary}

Adolescents might face one or more than one disease at a certain period of their lives. Adolescents, are admitted sometimes for treatment of acute diseases such as pneumonia, meningitis, and sometimes to overcome some problems due to chronic diseases such as diabetes, cancer, chronic kidney disease. In this article, nursing approach about counseling and general health education given by pediatrics clinic education nurse to the inpatient adolescents is discussed. (Turk Arch Ped 2011; 46 Suppl: 12-4)

Key words: Adolescent, counseling, general health education, education nurse

\section{Giriş}

Tüm ergenler yaşamlarını bu döneminde bir ya da birden çok hastalıkla karşılaşırlar. Bu hastalık ergenin kişiliği, yaşı, içinde bulunduğu koşullar, hastalığın tipi ve süresi gibi çok çeşitli etkene bağlı olarak onda strese neden olur. Bu durumda stresin etkileri geçici olabileceği gibi, ergen üzerinde tüm yaşamı boyunca sürecek kalıcı izler de bırakabilir.

Ergenler, bazen pnömoni, menenjit gibi akut hastalıkların tedavisi, bazen de diyabet, kanser, kronik böbrek yetmezliği vb. gibi kronik hastalıklarla ilgili ortaya çıkan bazı sorunların çözülmesi için hastaneye yatıılarak tedavi edilirler. Bu bağlamda İstanbul Üniversitesi Cerrahpaşa Tıp Fakültesi Hastanesi Çocuk Sağlığı ve Hastalıkları
Anabilim Dalı'nın yataklı servis ve ünitelerinde yatarak tedavi gören hasta ve hasta yakınlarına 1 Kasım 1994'ten beri eğitim hemşiresi tarafından danışmanlık hizmeti ve genel sağlık eğitimi verilmektedir. Burada eğitim verilen hasta grubu ergen hastalardır. Bu hastalara 10-15 dakika yüz yüze eğitim verilmektedir. Eğitim süresi hastaların sorulanı ve kendileriyle ilgili paylaşımları nedeniyle uzayabilmektedir.

\section{Eğitim verirken dikkat edilmesi gereken noktalar}

1) Ergen ve eğitimci birbiriyle tanışmalıdır.

2) Ergene eğitim programı tanıtılmalıdır.

3) Etkileşim ve iletişimin öneminden bahsedilmelidir.

4) Ergenin eğitimle ilgili soruları yanıtlanmalıdır.

5) Gizliliğe önem verilmeli, mahremiyete saygılı olunmalıdır.

Yazışma Adresi/Address for Correspondence: Mahi Bülgün,

İstanbul Üniversitesi Cerrahpaşa Tıp Fakültesi Hastanesi, Çocuk Sağlığı ve Hastalıkları Anabilim Dalı, İstanbul, Türkiye E-mail: mahibulgun@mynet.com Türk Pediatri Arşivi Dergisi, Galenos Yayınevi tarafindan basılmıștr. / Turkish Archives of Pediatrics, Published by Galenos Publishing. 
6) Eğitimci dikkatli ve etkin bir dinleyici olmalıdır.

7) Ergenin eğitime katkı ve katıımı sağlanmalıdır, soruları yanıtlanmalıdır.

8) Eğitimci tarafından daha sonraki bir süreçte ergen odasında ziyaret edilerek eğitim sonucu denetlenmeli ve desteklenmelidir.

\section{Eğitim konuları}

1. İletişim

- Tanışma,

- Ergen hastanın refakatçisi, ailesi, sağlık personeli, aynı odayı paylaştığı hasta ve refakatçisi ile serviste yatan akranları ve ziyaretçilerle iletişimi

\section{Ziyaretçiler}

- Hasta ve refakatçisi için ziyaretin önemi

- Ziyaretçilerin uyması gereken kurallar

\section{Hijyen}

A- Bireysel hijyen

a) El hijyeni

- El yıkama

- El dezenfektanının doğru kullanımı

b) Ağız ve diş sağlığı

- Diş firçalama tekniği

- Diș ipi kullanma tekniği

- Düzenli olarak diş hekimi kontrollerinin yapılması

c) Banyo

ç) Saç temizliği ve bakımı

d) Tırnak temizliği ve bakımı

e) Cilt bakımı

f) Göz bakımı

g) Kulak bakımı

g) Burun-boğaz bakımı

h) Ayak bakımı

I) Perine bakımı

i) Vücutta istenmeyen tüy ve kılların temizliği

j) Koku ve ter giderici maddelerin kullanımı

k) Sağlıklı giyinme

\section{B-Yaşanılan ortamın temizliği}

a) Yerlerin ve yüzeylerin temizliği

b) Lavabo ve tuvaletlerin temizliği

c) Buzdolaplarının temizliği

ç) Yiyeceklerin ve içeceklerin temizliği

d) Besinlerle ilgili hijyen kuralları

e) Mutfakla ilgili hijyen kuralları

f) Böceklerin enfeksiyon hastalıklarının bulaşması üzerindeki etkisi ve böceklerle mücadele

\section{Tıbbi atık yönetimi}

a) Evsel atıklar

b) Tıbbi atıklar

c) Cam atıklar

d) Kağıt atıklar

\section{Ergenlerin eğitimciyle paylaşımları}

Ergenler; okul, kız ve erkek arkadaşları, etkin olarak ilgilendikleri spor ya da sanat dalları, SBS, ÖSS.. gibi büyük sınavlar ve hastalıkları nedeniyle yaşadıkları stres ile gelecek kaygılarını eğitimciyle paylaşmaktadırlar.

\section{Eğitimde yaşanılan sorunlar}

a) Ergenin bedensel engelleri (körlük, konuşamama, sağırlık vb.).

b) Zeka ve kapasitesinin sınırlı olması.

c) Yapılan eğitimin gerekliliğine inanmaması.

ç) Eğitim sırasında psikolojik durumunun uygun olmaması.

d) Öfke ve korku içinde olması.

e) Kendini baskı altında hissetmesi.

f) Dil sorunu (Türkçe bilmemesi).

g) Fiziksel ortamın (oda, ışık, Isı vb.) uygun olmaması.

h) Ergenin aynı odayı paylaştığı hasta ya da hasta yakınının eğitimi engelleyecek şekilde davranması (yüksek sesle telefonla konuşması vb.).

ı) Sağlık ekip üyelerinin herhangi birinin eğitim ortamını bozacak şekilde davranması.

\section{Çözüm önerileri}

1) Bireysel ve grup eğitimlerinin yapılacağı bir eğitim odası olmalıdır.

2) Bu eğitim odasının bina içindeki konumu, havalandırma, ıSı, ışık, ses ve oturma düzeni eğitime uygun olmalıdır.

3) Bu odada yeterli sayıda rahat oturulabilen sandalyeler ile grup eğitimlerinde öğrenenler arasındaki etkileşimi teşvik edecek şekilde yuvarlak ya da oval biçiminde masaların konması önem taşımaktadır.

4) Eğitim ortamının; kitap, dergi, slayt, televizyon, video gibi görsel- işitsel araçlarla; modeller, maketler ve bilgisayar gibi araçlarla düzenlenmesi gerekmektedir.

5) Türkçe bilmeyen hastalarla iletişim kurmak için farklı dillerde çeviri yapabilecek yeterlilikte olan sağlık ekibi üyelerinden ve hasta yakınlarından yardım alınabilir.

6) Bedensel engeli olan ergene engel durumu göz önüne alınarak eğitim verilmelidir.

7) Çeşitli nedenlerle eğitim alamayan ergenlerin yakınlarına eğitim verilmelidir.

İstanbul Üniversitesi Cerrahpaşa Tıp Fakültesi Hastanesi Çocuk Sağlığı ve Hastalıkları Anabilim Dalı'nın yataklı servis ve ünitelerinde yatarak tedavi gören hasta ve hasta yakınlarına 1 Ocak 2010-1 Eylül 2010 tarihleri arasındaki yapılan toplam eğitim sayısı 830 'dur. Bunların 137'si ergen hastadır. 
Ergenlere danışmanlık yaparken ve genel sağlık eğitimi verirken hedeflenen; bireyde farkındalık yaratarak istendik davranış geliştirmesini sağlamaktır.

\section{Kaynaklar}

1. Ekşi A. Pediatrinin Psiko-sosyal Yönü. İçinde; Onat T ed. Çocuk Sağlı̆ı̆ ve Hastalıkları. İstanbul; Eksen Yayınları: 1996; 1092-7.

2. Ertem I. Çocuk Sağlı̆ı̆ ve Hastalıklarına Psiko-sosyal Yaklaşım. İçinde; Ekşi A. Ben Hasta Değilim, İstanbul: Nobel Tıp Kitabevleri, 1999; 365-73.
3. Yörükoğlu A. Ergenlik. İçinde; Yörükoğlu A. Gençlik Çağı, İstanbul: Özgür Yayınları, 1998; 33-54.

4. Alikaşifoğlu M. Adolesana Verilmesi Gereken Koruyucu Sağlık Hizmetleri. İçinde; Ercan O, ed (s). Adolesan Sağlığı I. İ.Ü. Cerrahpaşa Tıp Fakültesi Sürekli Tıp Eğitimi Sempozyum Dizisi No:43, İstanbul: Kaya Basımevi, 2005; 29-38.

5. Ercan O, Adolesana Yaklaşım. İçinde; Ercan O ed (s). Adolesan Sağıı̆ı I. I..Ü. Cerrahpaşa Tıp Fakültesi Sürekli Tıp Eğitimi Sempozyum Dizisi No:43, İstanbul: Kaya Basımevi, 2005; 23-7.

6. Derman O Ergenlerde Psikososyal Gelişim. İçinde; Ercan O ed (s). Adolesan Sağlığı II, İ.Ü. Cerrahpaşa Tıp Fakültesi Sürekli Tıp Eğitimi Sempozyum Dizisi No:63, İstanbul: Aksu Basım Yayın, 2008; 19-21. 